\title{
التحليل المكاني لتوزع الدوائر الحكومية في مدينة المفرق باستخدام
}

\section{نظم المعلومات الجغرافية}

\author{
أ.م. عايد محمد عايد طاران م.م عاطف عايد الغميض \\ جامعة آل البيث/ معهد علوم الأرض والبيئة
}

الملخص:

تهدف هذه الدراسة إلى تطبيق منهجية التحليل المكاني لمواقع الدوائر الحكومية في مدينة المفرق، باستخدام تقنية نظم المعلومات الجغرافيـة (GIS)، عن طريق أدوات التحليل المكاني المتوفرة داخل بيئة برمجيات نظم المعلومات

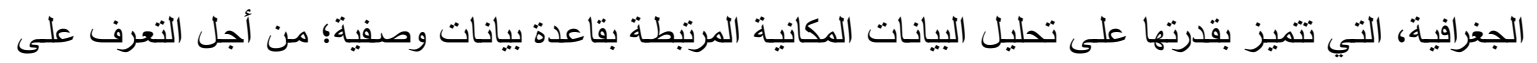
خصـائص المكان، مـن خـلال دراسـة العلاقـات المكانيـة للظــاهرة الجغرافيـة، ومعرفـة نمـط التوزيـع الجغرافي للمعـالم الجغرافية، وانتشارها على سطح الأرض. من فئ.

وقد اعتمدت الدراسة على المنهج الوصفي التحليلي في معالجة البيانات الرقمية، من خلال الاستعانة ببعض الأساليب الإحصائية، والتمثيل البياني، والكارتوغرافي؛ من أجل إبراز الخصائص المكانية لتوزيع الدوائر الحكومية في مدينة المفرق، وكذلك برنامج التحليل الاحصائي (SPSS)، وتوصلت الدراسة إلى وجود تباين واضح في التوزيع الجغرافي للدوائر الحكومية؛ إذ نركزت معظم الدوائر الحكومية في الجهة الثرقية من مدينة المفرق. كما أظهرت الدراسة أن نمط نوزيع هذه الدوائر هو نمط عشوائي.

الكلمات الدالة: التحليل مكاني؛ الدوائر الحكومية؛ نظم معلومات جغرافية؛ صلة الجوار ، المسافة المعيارية، اتجاه الانتشار •

المقدمة: تعدُّ الخدمات العامة من الأمور الهامة التي يُعنى بها الإنسان، حيث تلامس واقع حياته اليومية، سواء أكانت هذه الخدمات إدارية أو صحية أو تعليمية أو دينية أو سياحية أو نرفيهية، ويعد الاهنمام بالخدمات من الأمور التي تظهر مدى تقدم الدول في مجال التخطيط الحضري المستقبلي، حيث أن

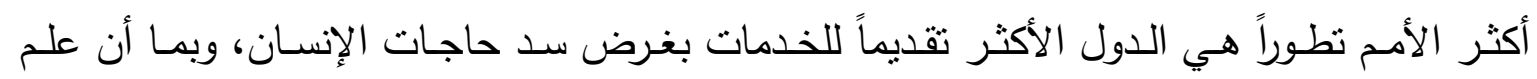
الجغرافيا يهتم بدراسـة العلاقة بين الإنسـان والخدمات التي تقدم لله، فان الجغرافي يهتم بدراسـة هذه 
الخدمات ومدى تجمعها ونتتتها وارتباطها بالكثافة السكانية، وقد أدى ذلك كله إلى ظهور فرع جديد في الجغرافيا البشرية، اصطلح على تسميته بجغرافية الخدمات. وتعدُّ الدوائر الحكومية من أهم الخدمات الإدارية التي تهم السكان؛ الأمر الذي يتطلب تقبيم مدى مالائمة التوزيع المكاني للدوائر الحكومية في مدينة المفرق، و مدى تتاسبها مع توزع وحاجات سكان المدينة في هذه الدراسة. وتعدُّ نظم المعلومات الجغرافية (Geographic Information System (GIS) تقنية حديثة نسبيَّا، تساعد الباحث الجغرافي في الكثف عن أنماط التوزبع الجغرافي، لمواقع الظواهر على سطح الأرض، كما تساعد هذه التقنية على جمع البيانات وتخزينها وتحليلها وإخراجها بطريقة تمكنه من تفسير، وتحليل ارتباط المتغيرات بصورة لم تكن متاحة من قبل، وأهم ميزة لهذه التقنية هي القدرة على ربط المعلومات المختلفة، وتوظيفها في تقديم الحلول للمشكلات المطروحة على أساس توفير العديد من البدائل التي يختار منها ما يناسب الباحث وأغراض الدراسة، (الصالح والسرياني: . . . بم). مشكلة الاراسة: من

إنَّ التغيـرات الديموغرافيـة الناتجـة عـن الزبـادة السـكانية العاليـة سـواء بفعـل الزبـادة الطبيعيـة للسكان أو بفعل الهجرة السكانية التي تعرضت لها محافظة المفرق بشكل عام ومدينة المفرق بشكل خاص خاصسة في الآونـة الأخيرة نتيجة هجرة اللاجئين السوريين، إضـافة إلى التغيرات الاجتماعية والاقتصادية في مدينة المفرق أدت إلى زيادة الطلب على الخدمات باختلاف أنواعها، واستجابة لذلك تم إنتـاء العديد من الدوائر الحكومية في المدينة والتي تتبع لمختلف الوزارات، إلا أن توزعها داخل المدينة كان بشكل عثوائي ولم يأخذ بعين الاعتبار الكثافات السكانية في أحياء المدينة مما أدى ذلك إلى إيجاد صعوبة في وصول المواطنين إلى هذه الخدمات وخاصـة الخدمات الإدارية، لذلك جاءت هذه الدراسة لتحليل العلاقة بين توزع الدوائر الحكومية والتوزع السكاني في مدينة المفرق، ومدى تأثير التوزع الجغرافي للدوائر الحكوميـة على التوزع الجغرافي للتجمعات السكانية، والمسـافات بين مواقع الدوائر الحكومية والتجمعات السكانية في منطقة الدراسـة، ولذلك تسعى هذه الدراسـة إلى الإجابة عن التساؤلات الآتية:

ا. كيف تتوزع الدوائر الحكومية في مدينة المفرق؟ وهل توزعها كان منتظما ام عشوائيا؟ r. ما مدى تتاسب نوزع الدوائر الحكومية مع الكثافات السكانية في مدينة المفرق؟ 


\section{أهمية الدراســة ومسوغاتها:}

تتبع أهمية هذه الدراسة من ملامستها لواقع ومنطلبات الحياة اليومية لدى الإنسان، إذ تم إنشاء

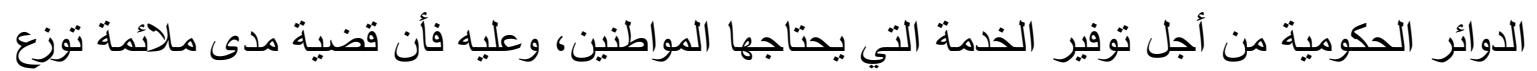

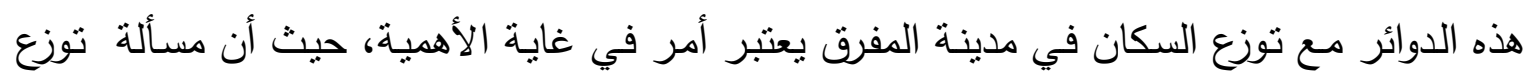

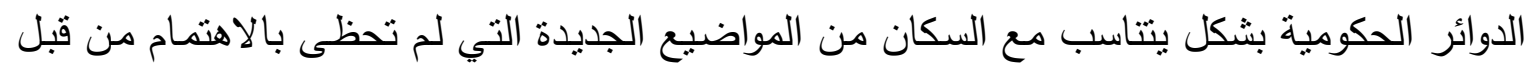

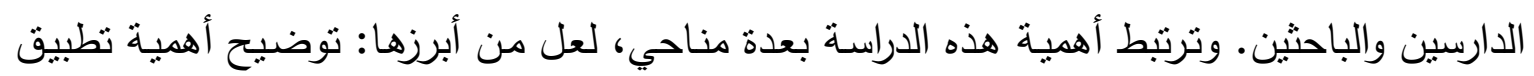

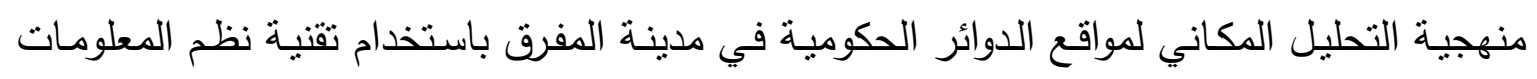
الجغرافية كأداة للتحليل المكاني بهدف إظهار مدى إمكانية استخدام هذه التقنية لاختيار مواقع الدوائر

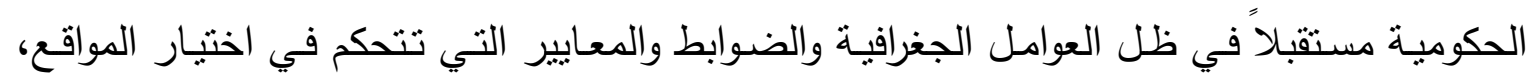
والمشاكل التي قد تعوق ذلك، ويعزز من أهمية الدراسة استخدام بعض الطرق الإحصائية في هذه

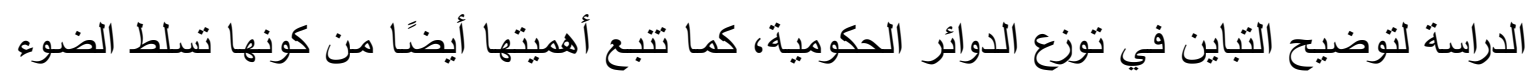
على الخصائص المكانية لمواقع الدوائر الحكومية في المدينة.

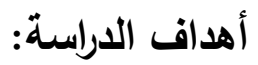

تسعى هذه الدراسة إلى تحقيق الأهداف التالية:

1. التعرف بالنمط المكاني لتوزع الدوائر الحكومية في مدينة المفرق.

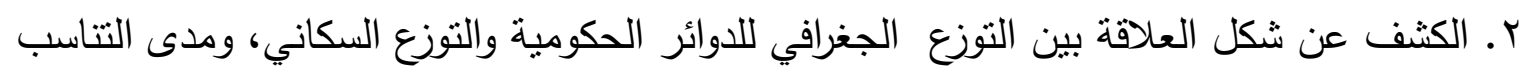
بينهما في مدينة المفرق. r. دراسة مدى الحاجة إلى تطوير الدوائر الحكومية في ضوء الزيادة السكانية العالية في مدينة

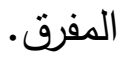

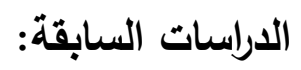
يلحظ أن هناك فقر بالدراسات التي تتعلق بتحليل نمط توزيع الدوائر الحكومية في الأردن، إلا أن هناك العديد من الدراسات التي عالجت موضوع التحليل المكاني لبعض المرافق والخدمات الأخرى.

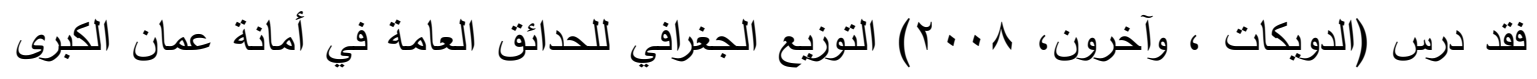

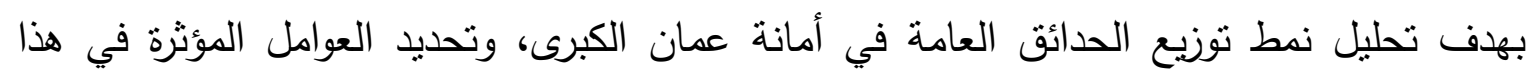

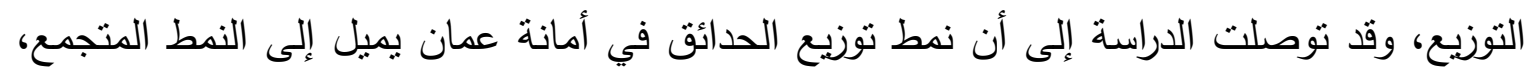

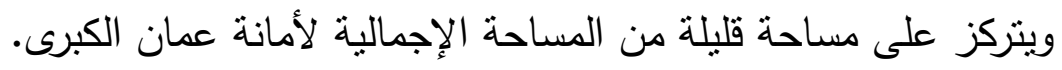


وقام (الغزاوي، علي عبد العباس، ^ . . ץ) بدراسة نمط التوزيع المكاني لمراكز الاستيطان الريفي

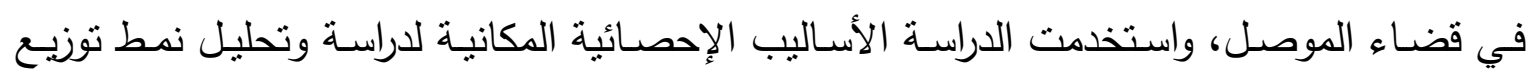

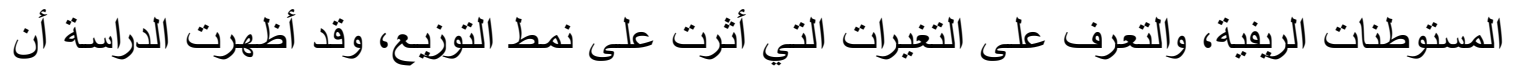
مراكز الاستيطان الريفي في المنطقة ذات نمط متباعد، كما أظهرت نتائج الدراسة أيضـا بان المركز المكاني للمستوطنات الريفية يقع في وسط المنطقة، وان اتجاه التوزيع فيها اتخذ شكلا بيضاويا ويمتد باتجاه شمالي غربي وجنوبي شرقي •

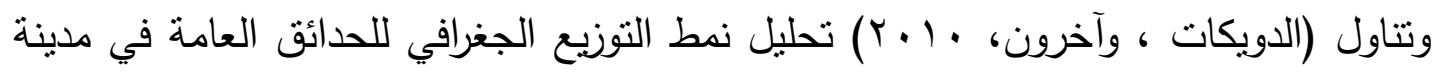
اربد باستخدام نظم المعلومات الجغرافية، بهذف التعرف إلى نمط توزيع الحدائق في مدينة اربد،

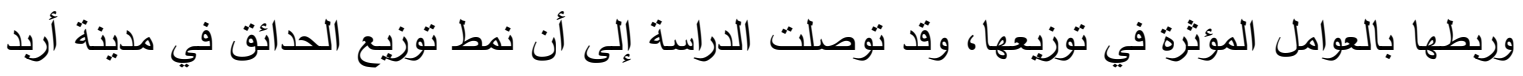
هو نمط عشوائي لا يتتاسب مع التوزيع الجغرافي للسكان في أحياء المدينة المختلفة. وعالج (عنايا ، نضال، ( • ب) توزيع وتخطيط الخدمات العامة في مدينة قلقيلية بالاستعانة

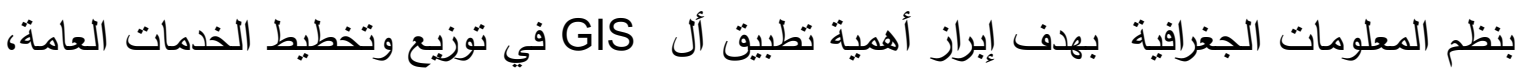
والتعرف على أهم الأسباب التي تعيق تطبيق المعايير التخطيطية في المدينة والتغلب عليها، فضلاًا

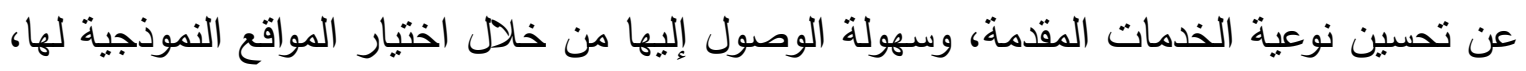

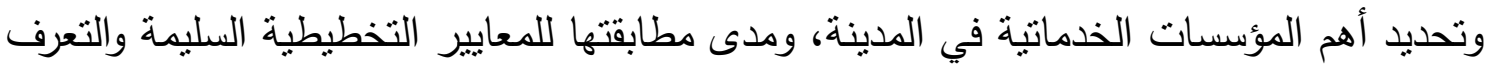
بجوانب النقص فيها، وقد تم الاعتماد في هذه الدراسة على المنهج الوصفي من خلال استعمال أدوات البحث العلمي من استبانة وملاحظة ومقابلة، وقد توصلت الدراسة إلى عدم وجود انتظام في توزيع رياض الأطفال، بالإضافة إلى عدم مطابقة عدد منها للمعايير التخطيطية، كما أظهرت وجود ودئه

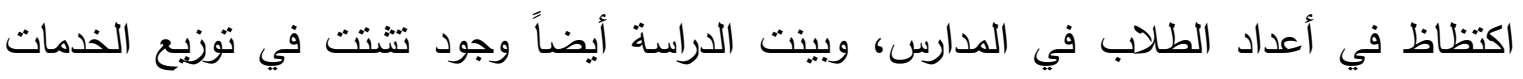

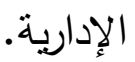

وتتاول (الجماصي، وآخرون، Y ( • ب) تحليل أنماط توزع المساجد في مدينة غزة (فلسطين) باستخدام نظم المعلومات الجغرافية، وهدفت هذه الدراسة إلى إيجاد المعايير التخطيطية المناسبة

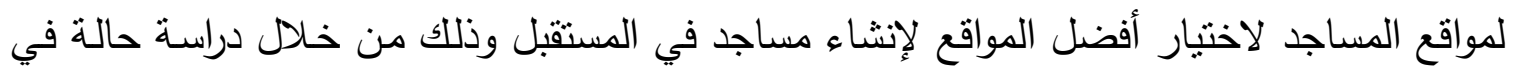
منطقة حي الثيخ رضوان، وتكمن أهية هذا البحث في تحليل وتقييم نمط المساجد من خلال المنهج الوصفي التحليلي باستخدام تكنولوجيا نظم المعلومات الجغرافية، وقد أظهرت الدراسة إمكانية تطبيق معايير تخطيطية في أماكن مختلفة في قطاع غزة للتوصل إلى أفضل الحلول المتاحة. 


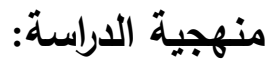

تم الاعتماد في هذه الدراسة على المنهج الوصفي التحليلي في الكثف عن نمط نوزع الدوائر الحكوميـة والسكان في مدينـة المفرق، وقد استخدمت بعض الطرق الإحصـائية الكميـة في التحليل

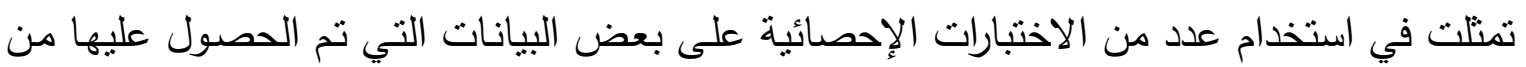
دائرة الإحصـاءات العامـة، ومن هذه الاختبارات مربع كاي، ومنحنى لورنز والتي تم استخدامهما

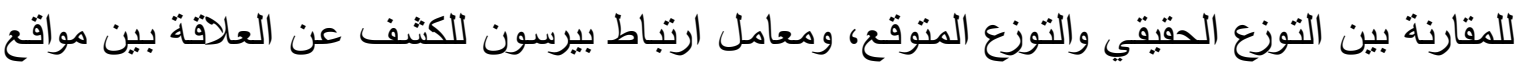
الدوائر الحكومية والكثافة السكانية، كما تم تطبيق بعض التقنيات والاختبارات الكارتوغرافية المتوفرة

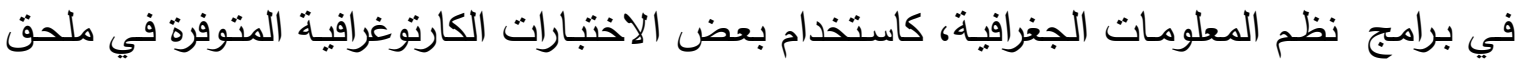

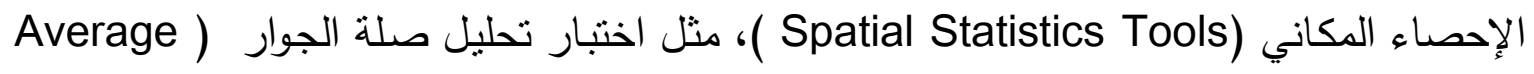
) لمعرفة نمط انتشار الدوائر الحكومية في مدينة المفرق، والمسافة المعيارية

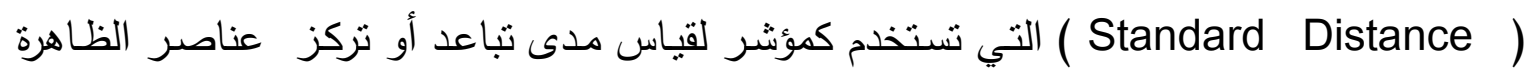

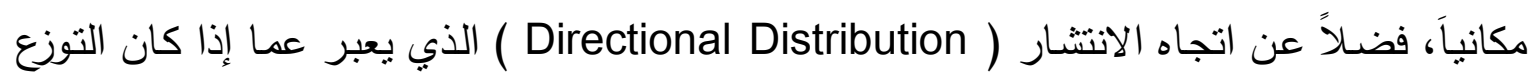
المكاني للظاهرة له اتجاه محدد ام لا، والمركز المتوسط ( Mean Center ) الذي يستخدم لمعرفة الموقع المتوسط لظواهر الدراسة. مصادر البيانات: تتمثل مصادر البيانات فيما يأتي:

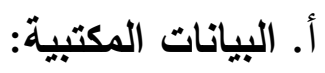

تتضمن الوثائق والدراسات السابقة المتعلقة بمدينة المفرق من رسائل جامعية، وبحوث، وتقارير

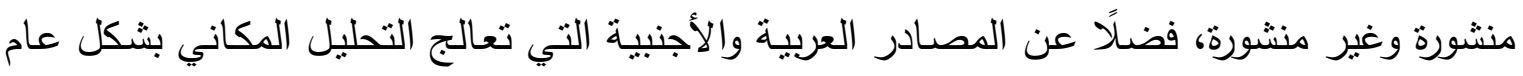
وموضوع الدراسة بشكل خاص.

ب. المؤسسات التي تثوافر فيها بعض البيانات، وهي:

* دائرة الإحصـاءات العامـة وتم الحصـول منها على نتائج التعداد السكاني الرسمي للفترة الزمنيـة

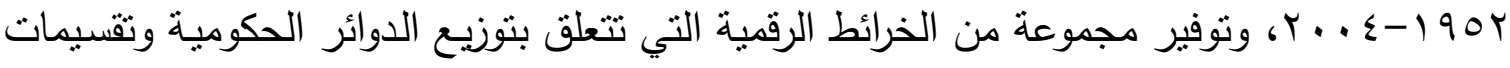

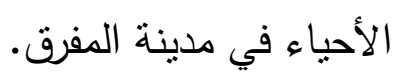

* بلدية المفرق إذ تم الحصول منها على المخططات الهيكلية والتنظيمية لمدينة المفرق فيما يتعلق بتوزيع الخدمات العامة وخدمات البنية التحتية والتقسيمات الإدارية للمدينة خلال فترة الدراسة. 


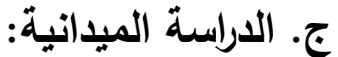

تمنلت الدراسة الميدانية بالقيام بجولات ميدانية استطلاعية قام بها الباحث للتعرف على المدينة

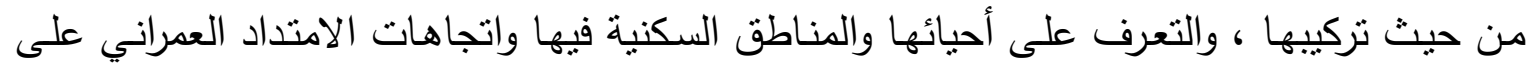
ارض الواقع، والتأكد من صحة التفسير والتحليل لتوزع الدوائر الحكومية في مدينة المفرق.

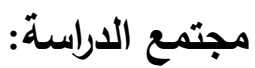

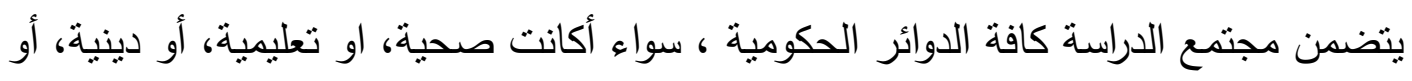

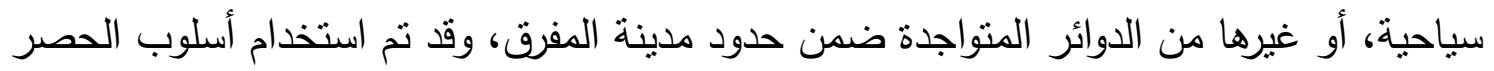

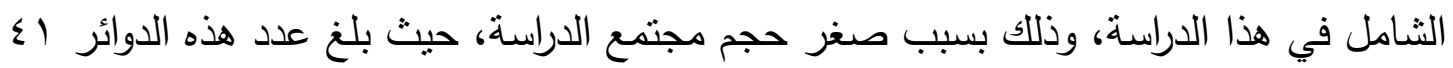
دائرة حكومية تتبع لجهات ووزارات مختلفة للدولة.

منطقة الدراسة: - م

تقع مدينة المفرق إلى الثمال الثرقي من المملكة الأردنية الهاشمية وتبعد عن العاصمة عمان

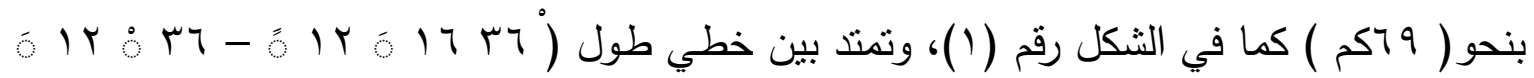

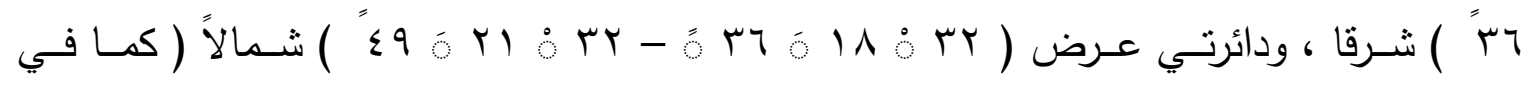
الثكل رقم ا )، وقد سميت "بالمفرق" لوقوعها على مفترق الطرق الدولية المتجهة إلى سوريا شمالا والسعودية جنوبا والعراق شرقا وفلسطين غربا. 
الشكل (1). موقع مدينة المفرق الأردن

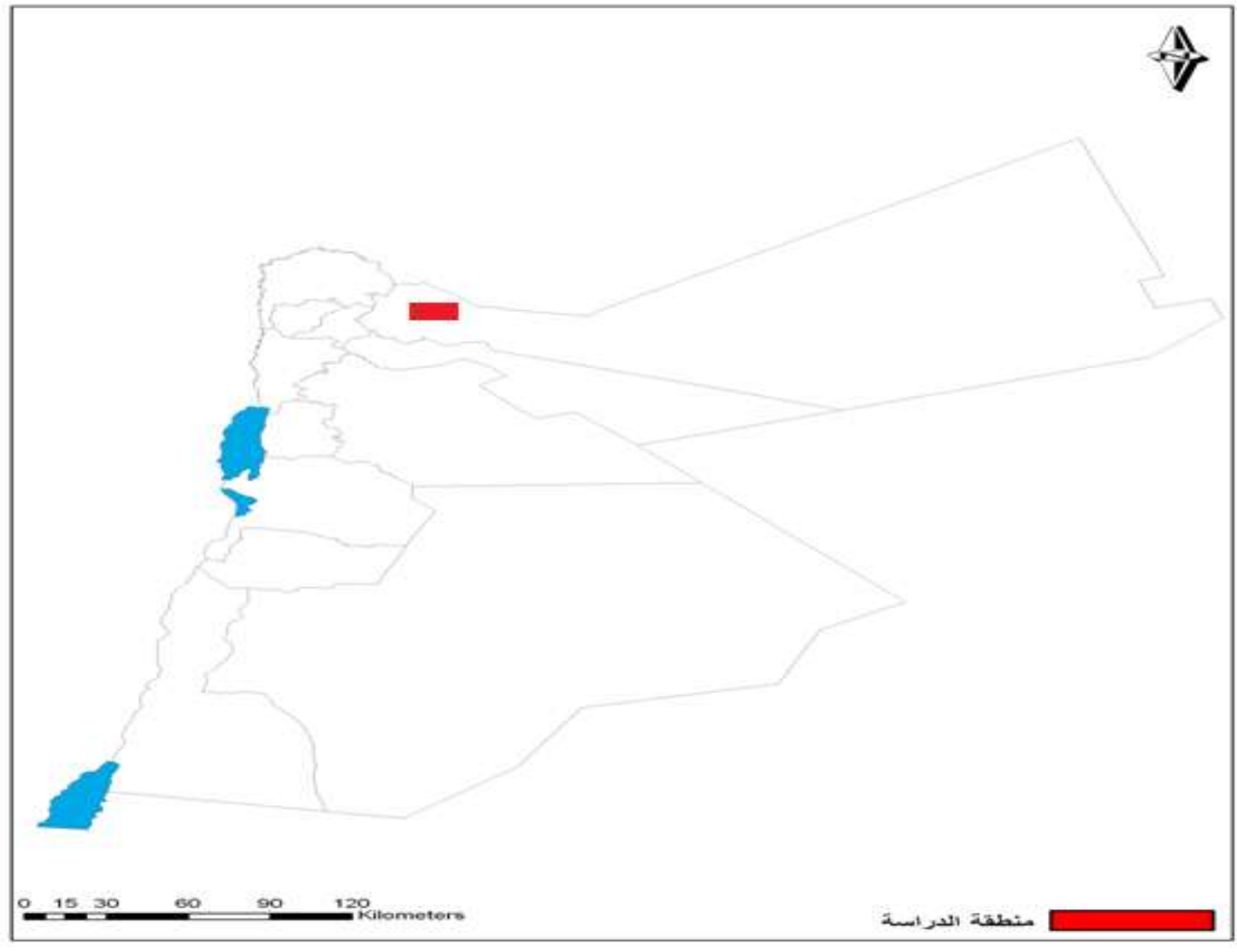

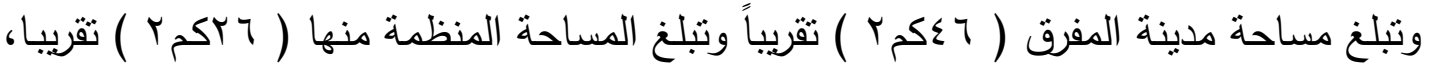

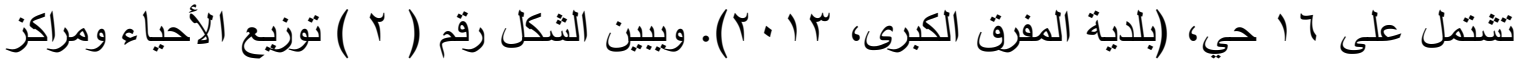

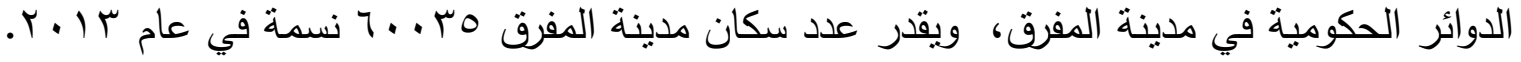

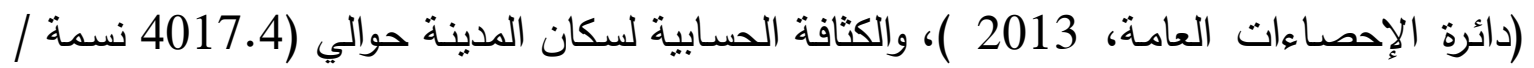

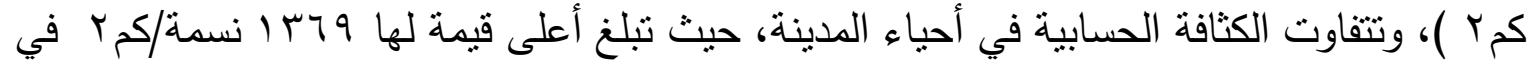

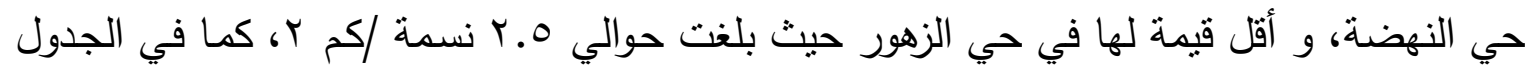
رقم( ( )، الذي يمثل توزيع السكان على أحياء مدينة المفرق، فضلاً عن المساحة والكثافة الحسابية

لكل حي. 


\section{الشكل (Y). أحياء مدينة المفرق.}

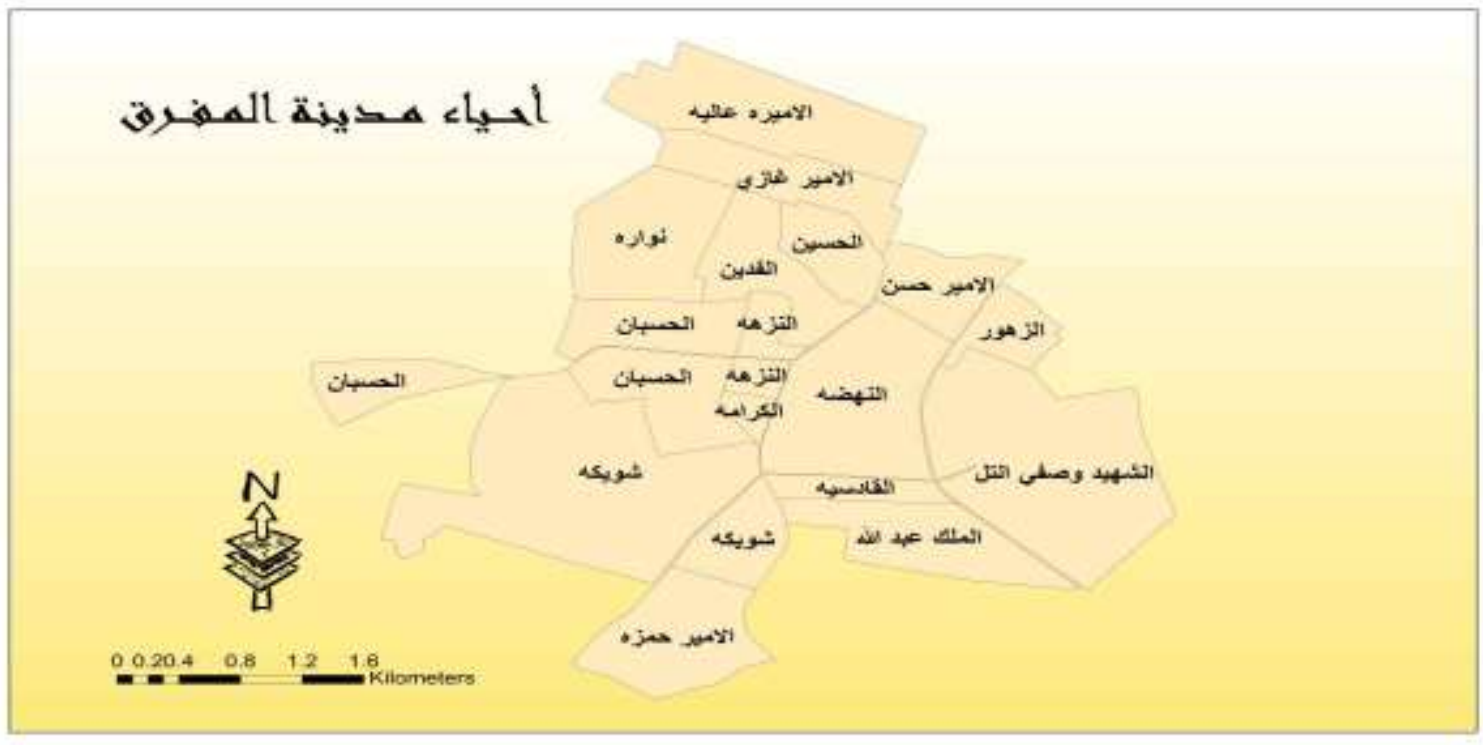

الجدول ( 1 ). أعداد السكان والمساحة والكثافة الحسابية لأحياء مدينة المفرق.

\begin{tabular}{|c|c|c|c|c|}
\hline \multirow{2}{*}{ الكثافة الحسابية } & \multirow[t]{2}{*}{ المساحة/ كمب } & \multicolumn{2}{|r|}{ عدد السكان } & \multirow{2}{*}{ اسم الحي } \\
\hline & & إناث & ذكور & \\
\hline 289.2516 & $\cdot V 4 \Lambda \varepsilon$ & 2087 & 2049 & الملك عبد الله \\
\hline 189.3298 & Y.V००५^V & 1348 & 1360 & شويكة \\
\hline 33.22314 & $\cdot \Lambda \leqslant \Lambda \cdot r r$ & 239 & 236 & الأمير حمزة \\
\hline 192.0213 & $1.0 Y \cdot 1 r 4$ & 1360 & 1386 & الحسبان \\
\hline 108.8373 & $.91 \leqslant 14$ & 743 & 813 & نواره \\
\hline 1368.962 & $1 . r \vee \circ \Lambda \cdot V$ & 9337 & 10239 & النهضة \\
\hline 477.9927 &.$r q 1 Y \cdot r$ & 3279 & 3556 & الحسبن \\
\hline 372.6038 & $\cdot . \leqslant \leqslant \wedge \leqslant \cdot r$ & 2609 & 2719 & الأمير حسن \\
\hline 2.523277 & $\cdot r \ldots \leq \mu$ & 12 & 24 & الزهور \\
\hline 48.86746 & r..79.V^ & 332 & 367 & الثهيخ وصفي التل \\
\hline 176.4611 & . YYYTQ & 1201 & 1322 & القادسية \\
\hline 11.27064 & $\because \cdot q r Y V \leq$ & 77 & 84 & الكرامة \\
\hline 191.769 & $\because Y \wedge \leq \leqslant \wedge q$ & 1317 & 1426 & النزهة \\
\hline 166.5363 & $\cdot .7109 . r$ & 1160 & 1222 & القدين \\
\hline 272.8503 & . TrOVY & 1865 & 2037 & الأمير غازي \\
\hline 114.8932 & $1.1 V T 19 Y$ & 790 & 852 & الأميرة عاليه \\
\hline
\end{tabular}


وقد شهدت المدينة حركة عمرانية نشطة، حيث يعد ذلك مؤشرا على الزيادة السكانية العالية التي شـاهدتها المدينة وعلى التوسع في الاستعمال السكني. ونظرا لوقوع جامعة آل البيت ضمن حدود

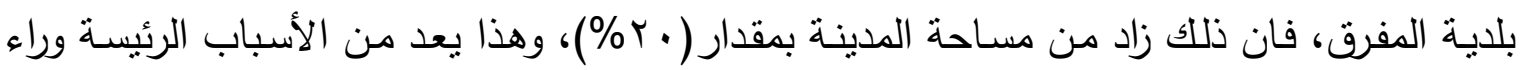

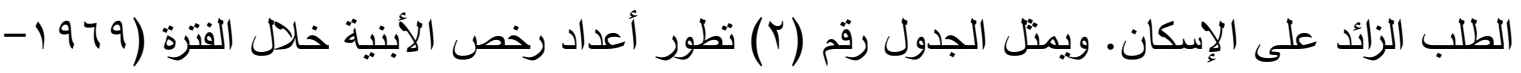

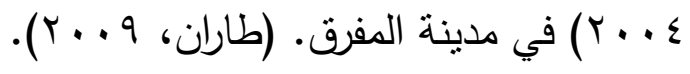

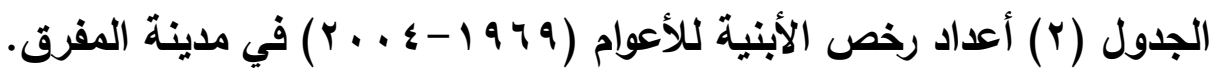

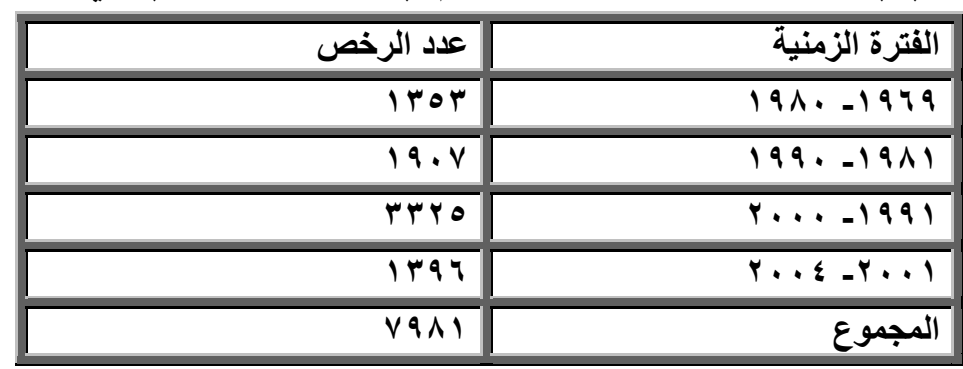

المصدر : عمل الباحث بالاعتماد على بيانات سجلات دائرة التظيم بلاية المفرق الكبرى، ؛ . . . .

وقد كان الامتداد العمراني في مدينة المفرق خلال فترة السبعينات من القرن الماضي أفقياً، و كان يمتهن سكانها التجارة و الزراعة، وقد عانت منطقة الدراسة خلال فترة السبعينات من قلّة الدوائر

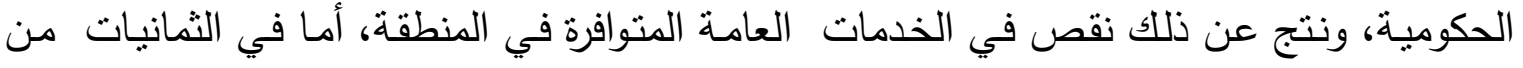

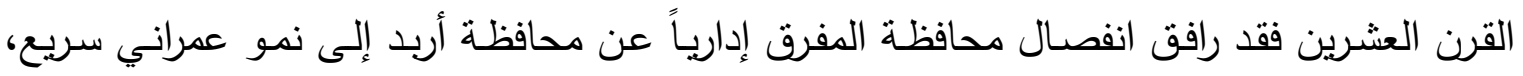
وتطور في البنية التحتية ومستوى الخدمات، غير أن فترة التسعينات تعد فترة انفجار غمرت المدينة

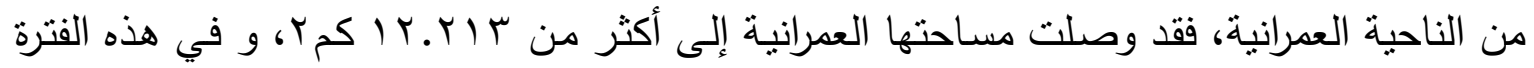

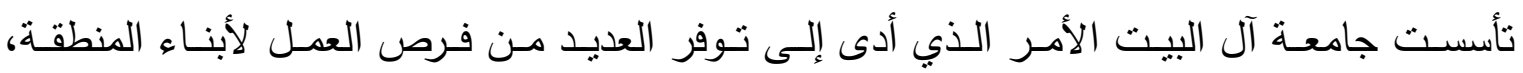

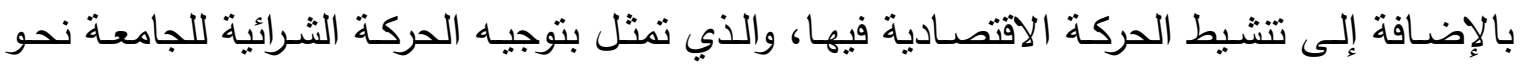

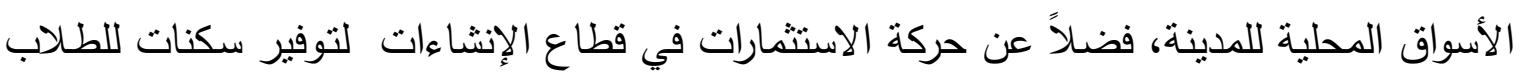
والطالبـات والموظفين، واستتر النمو في الامتداد العمراني في مدينـة المفرق خـادل مطلكع القرن

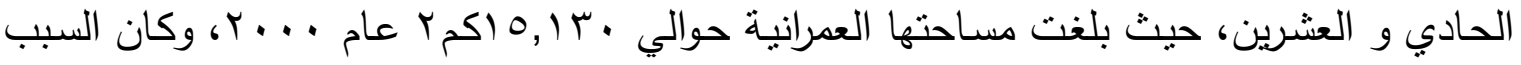

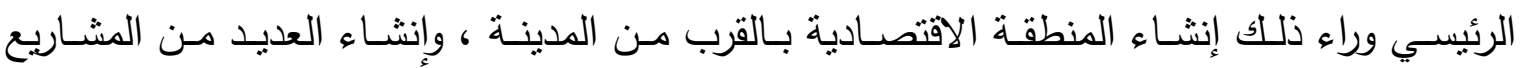
الاقتصادية والتتموية والمدن الصناعية التي عملت على توفير فرص عمل لأبناء المدينة. و يظهر

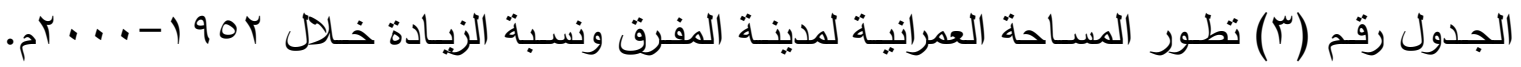

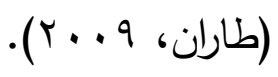




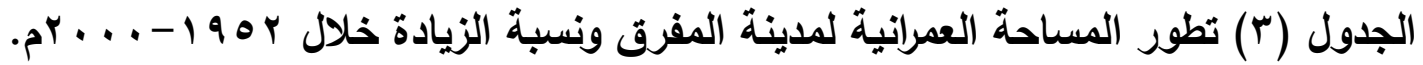

\begin{tabular}{|c|c|c|}
\hline نسبة الزيادة المئوية \% & المساحة العمر انية/كمج & السنة \\
\hline & $\because .704$ & $190 Y$ \\
\hline$\Lambda .9$ & $1 . r \ldots$ & 197. \\
\hline 0.1 & r.r.q & 1971 \\
\hline ^. $\vee$ & $0 . r \leqslant \Lambda$ & $191 \varepsilon$ \\
\hline $1 \cdot .1$ & IY.YIT & 1994 \\
\hline Y.V & $10.1 \%$ & r... \\
\hline
\end{tabular}

نتائج التحليل:

التوزع الجغرافي للاوائر الحكومية في مدينة المفرق

بلغ مجموع عدد الدوائر الحكومية في مدينة المفرق اء دائرة حكومية تتبع لمختلف الوزارات في الدولة، و لا تتوزع هذه الدوائر بشكل منتظم، وإنما يقتصر توزعها بشكل عشوائي على بعض الأحياء، كحي النزهة، والحسن، والزهور، والفدين، و الأميرة عالية، والنهضة، والثهيد وصفي التل، و يمثل الثكل (r) التوزع الجغرافي للدوائر الحكومية على أحياء مدينة المفرق. الشكل (ب) توزيع الدوائر الحكومية على الأحياء السكنية في مدينة المفرق.

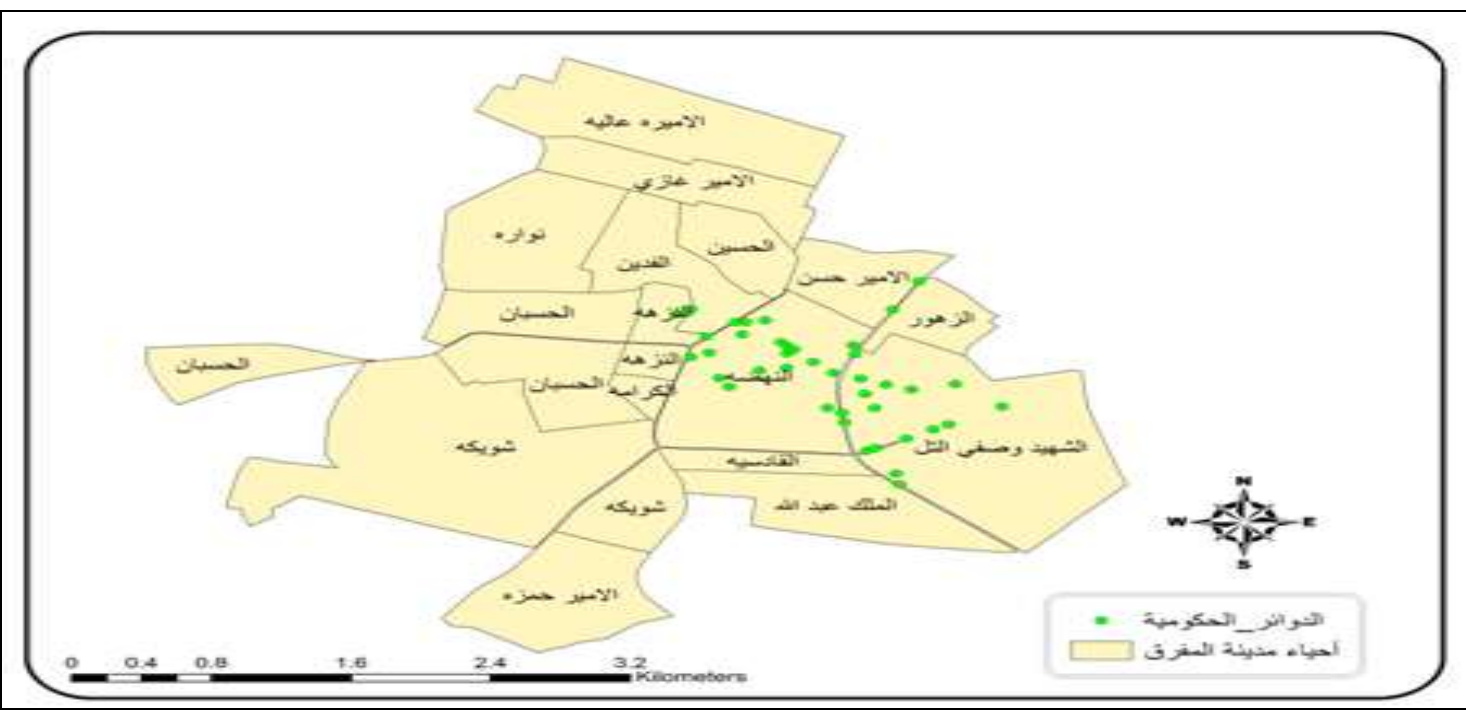

وعلى ضوء دراسة التوزع الجغرافي للدوائر الحكومية في مدينة المفرق، يلاحظ أن التوزبع كان

عشوائيا، وان نسبة الدوائر الحكومية في أحياء المدينة تختلف من حي لآخر ، ويبين الثكل رقم (ع) نسب توزع الدوائر الحكومية في احياء مدينة المفرق. 
الثكل (؟). نسبة الدوائر الحكومية في أحياء مدينة المفرق.

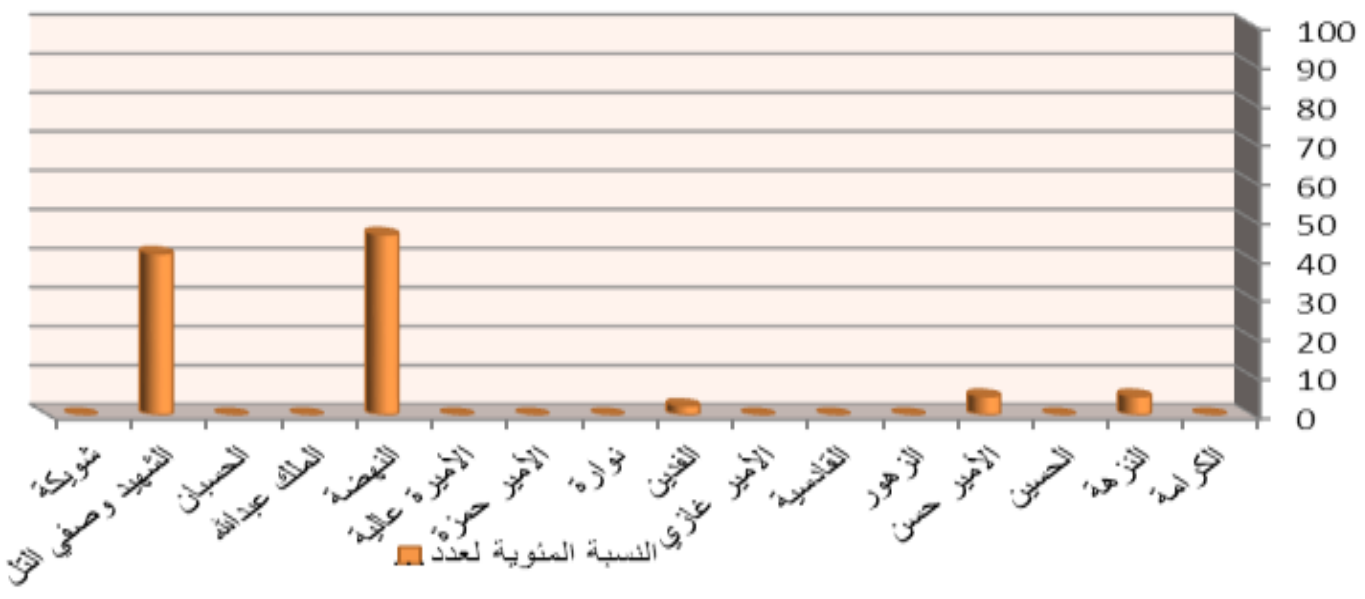

وقد تباين عدد الدوائر الحكومية المتواجدة في أحياء منطقة الدراسة بتتوع الجهات التي تتبع لها، فنجد أن اغلب الدوائر الحكومية تتواجد في كل من حي النهضة وحي الثهيد وصفي التل، وان القليل منها يتواجد في كل من حي الأمير حسين وحي النزهة وحي الفدين، في حين نجد أن باقي الأحياء

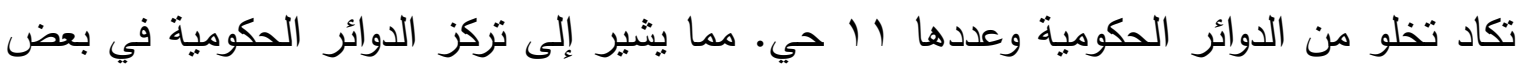
الأحياء فقط، الأمر الذي أدى إلى صعوبة تلقي الخدمات والحصول عليها من قبل سكان المنطقة، ويرجع سبب هذا التفاوت إلى نشوء أحياء جديدة، مما أدى إلى خلوها من الدوائر الحكومية، فضلًا

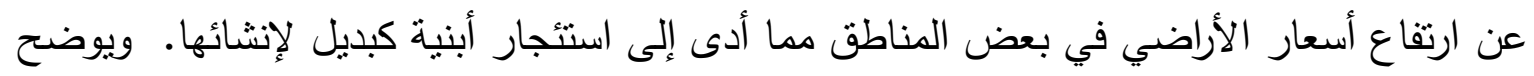
الثكل رقم (0) توزع الدوائر الحكومية المتواجدة في مدينة الدفرق حسب الوزارات والجهات التي تتبع

الشكل(0). الجهات والوزارات التي تتبع لها الدوائر الحكومية في المفرق.

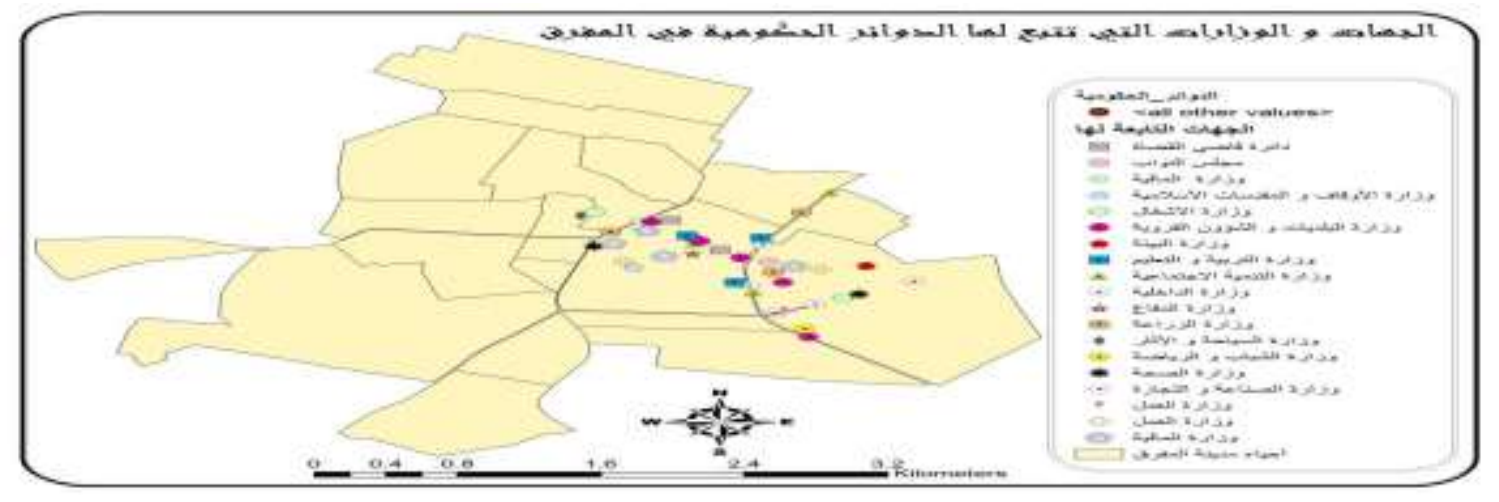


التحليل المكاني لنمط توزع الدوائر الحكومية في مدينة المفرق

تتيح نقنيـة نظم المعلومـات الجغرافيـة إجراء العديد من العمليات التحليليـة، سواء المكانيـة أو الإحصائية، التي يتطلب انجازها وقتًا طويلًا. ويأتي في مقدمتها عمليات النمذجة الرياء لفياضية المكانية

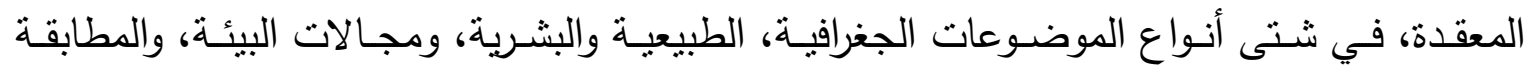
Overlaying، والتقييم المشروط للمواقع، وبناء السيناريوهات المستقبلية، وإنشاء النطاقات والممرات Site Suitability حول الظواهر، ووضع نماذج اختبار أفضل المواقع ونساء Buffers and Corridors Models، وتحليل التجاور Sproximity Analysis، والقياس المكاني Spatial Measurement، والتقريب المكاني Spatial Interpolation، إلى غير ذلك. الأمر الذي يفتح كثيرًا من الآفاق أمام

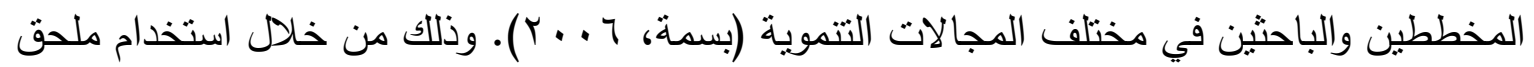
التحليل المكاني Spatial Analyst في برنامج نظم المعلومات الجغرافية، وقد تم تطبيق الاختبارات

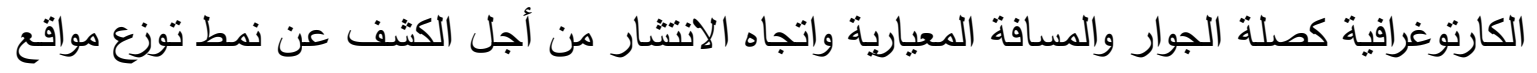
الدوائر الحكومية في مدينة الدفرق، كما ويتمثل استخدام الإحصاء في هذا الدراسة في معامل ارتباط

$$
\begin{aligned}
& \text { بيرسون، ومنحنى لورنز ، ومربع كاب. } \\
& \text { أولاً : التحليل الإحصائي }
\end{aligned}
$$

\section{Person Correlation ارتباط بيرسون}

يعمل معامل ارتباط بيرسون على قياس طبيعة وقوة العلاقة الخطية بين قيم متغيرين وتتراوح قيمته

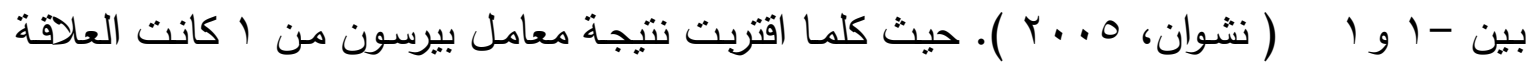
طردية، في حين كلما اقتربت من - 1 كانت العلاقة عكسية، أما إذا كانت نتيجة ارتباط بيرسون صفر فهذا يدل على عدم وجود علاقة بين المتغيرين. ويمثل الجدول رقم (ع) دلالات لمسنويات قيم

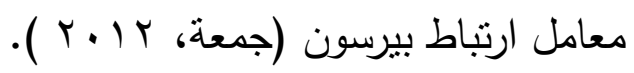

الجدول (ع). دلالات مستويات قيم معامل بيرسون.

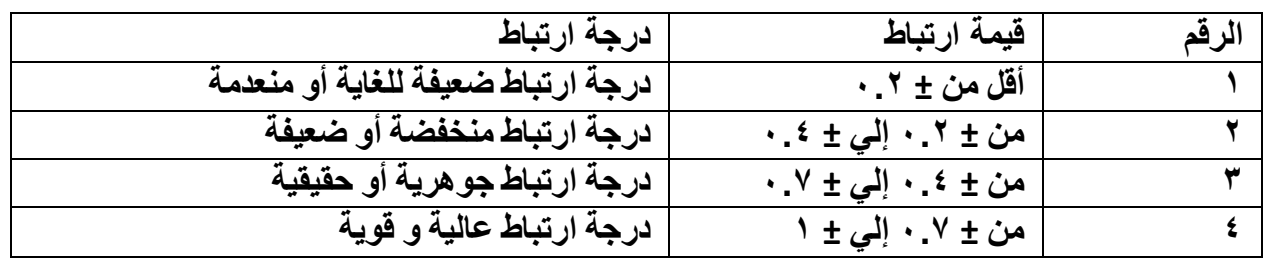


وتم استخدام معامل ارتباط بيرسون لقياس العلاقة بين عدد السكان في كل حي والدوائر الحكومية المتواجدة فيه، وقد تبيّن بعد إجراء هذا الاختبار من خلال الحزمة الإحصائية للعلوم الاجتماعية بأن العلاقة طردية، حيث بلغت قيمة معامل الارتباط r • ج. . عند مستوى ثقة 99\%، كما يبين الجدول (0) وتعبر هذه النتيجة عن تواجد الدوائر الحكومية في المناطق ذات الكثافة السكانية الكبيرة. الجدول (•). معامل ارتباط بيرسون.

\begin{tabular}{|ll|l|l|}
\hline Correlations & POP & Gov \\
\hline POP & Pearson Correlation & 1 & $.602^{* *}$ \\
& Sig. (1-tailed) & 16 & .007 \\
$\mathrm{~N}$ & 16 & 16 \\
\hline Gov & Pearson Correlation & $.602^{* *}$ & 1 \\
& Sig. (1-tailed) & .007 & \\
& $\mathrm{~N}$ & 16 & 16 \\
\hline
\end{tabular}

**. Correlation is significant at the 0.01 level (1-tailed).

\section{rorenz Curve منحنى لورنز}

و هو أسلوب بياني يستخدم لإظهار مدى العدالة في توزيع الظواهر ومدى النشتت في توزع أحدى الظواهر لمجتمعين أو عينيتين مختلفتين لأحدهما خاصية الامثلية في التوزيع، وبستخدمه الجغرافيون لأغراض مختلفة مثل: قياس درجة التركز ، والانتشار في التوزيعات المكانية ( صالح و السرياني،

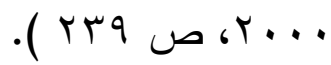
ويتكون منحنى لورنز من خطي توزيع: احدهما يمثل التوزيع المثالي، والآخر يمثل التوزيع الفعلي، وتعبر المسافة المحصورة بين التوزيع الفعلي و المثالي عن مدى العدالة في التوزيع، فكلما ابتعد خط التوزيع الفعلي عن المثالي دل ذلك على عدم العدالة في التوزيع والعكس صحيح، وبعد تطبيق هذا الأسلوب الإحصائي تبين أن جء \% من الدوائر الحكومية تتركز في حي النهضة، والذي يسكنه عب \% من مجمل سكان مدينة المفرق، في حين تخلو بعض الأحياء من الدوائر الحكوميـة مثل حي شويكة، والملك عبدا لله، والأمير حمزة، وتبين من خلال الرسم البياني لمنحنى لورنز الثكل (ج)، أن 
المسافة الفاصلة بيّن التوزبع المثالي والمتوقع أحيانا تقترب كما في حي النهضـة، وأحيانا تبتعد كما في حي شويكة على سبيل المثنال.

الثكل (7) منحنى لورنز لتوزيع الدوائر الحكومية في مدينة المفرق

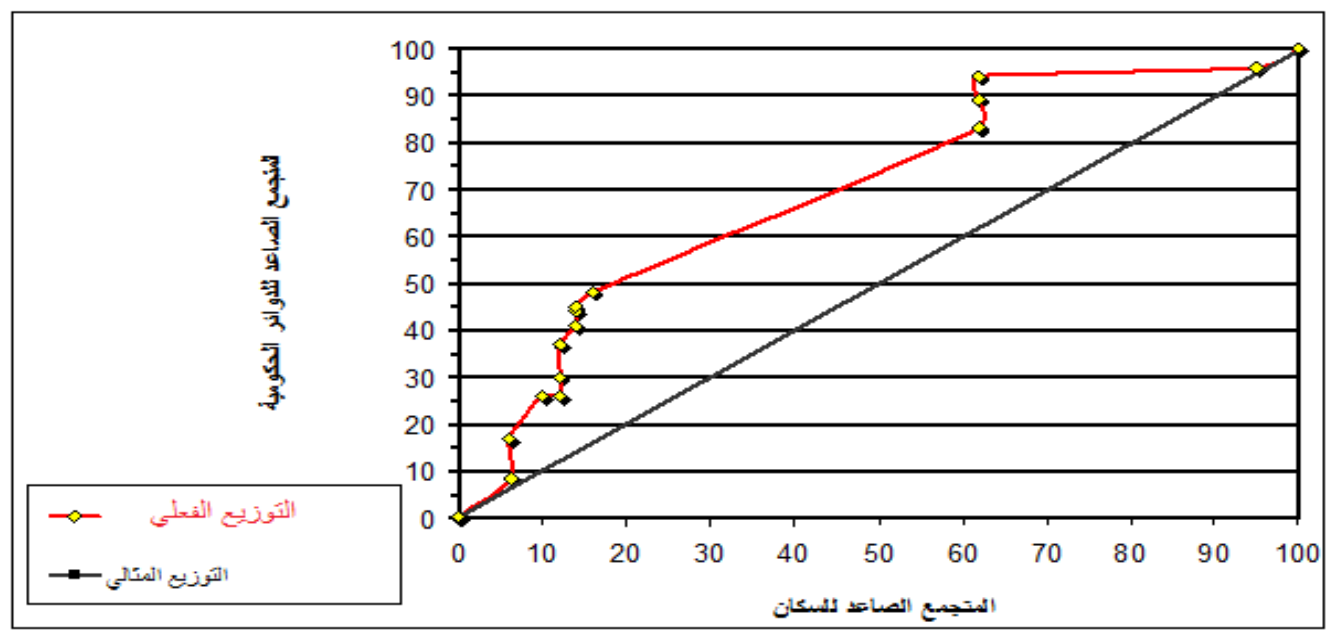

Chi Square r.

مربع كاي هو مقياس يستخدم للكثف عمـا إذا كانت نقطـة الظـاهرة الحقيقيـة تحت الدراسـة موزعة توزيعا عشوائيا، أم أنَّ توزيعها يشكل نمطاً معيناً بعيداً عن التوزيع العشوائي ،وذلك باستخدام صيغة رياضية إحصائية دقيقة ، ولذلك فان استخدام كاي تربيع هو اختبار للتأكد مبدئياً من أن نمط التوزبع بعيد عن العشوائية، وقيمة كاي نربيع تدل على درجة إقتراب أو ابتعاد نمط التوزبع الحقيقي المشاهد عن نمط التوزيع العشوائي النظري المتوقع للعدد نفسه من النقط الموزعة، (صالح والسرياني،

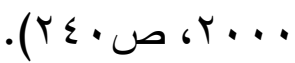

وبـتم إجـراء تحليـل توزيسع مربـع كـاي مـن خـلال تغطيـة منطقـة الدراسـة بشـبكة مـن المربعـات المتسـاوية، ومن ثم استخراج عدد الظواهر المتواجدة في كل مربع من المربعات، و مقارنة عددها بالعدد المتوقع ليكون التوزيع منتظماً ، (جمعة، r ( ا ب). وبناءً على ذلك تم تقسيم منطقة الدراسـة

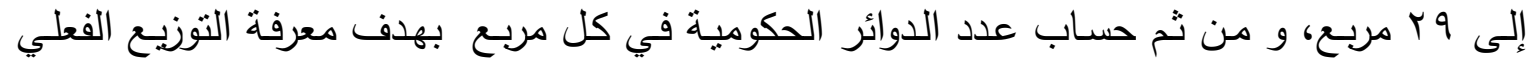

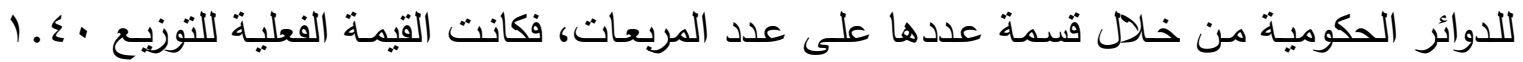


ويتم حساب قيمة مربع كاي وفق المعادلة التالية : ( دويكات، ( • ( )

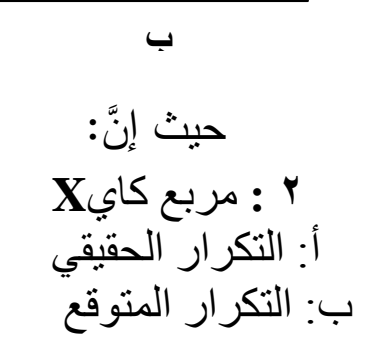

\begin{tabular}{|c|c|c|c|c|c|}
\hline 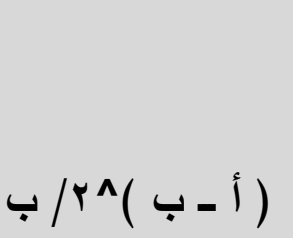 & $r^{\wedge}(ب-1)$ & أ - أ ب & 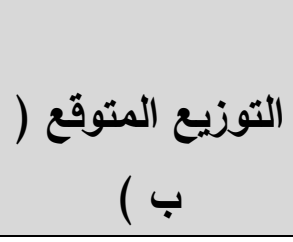 & التوزيـع & رقم \\
\hline 1.3666666667 & 1.8677777778 & -1.36667 & 1.3666666667 & 0 & 1 \\
\hline 9.659349593 & 13.20111111 & 3.633333 & 1.3666666667 & 5 & 2 \\
\hline 1.3666666667 & 1.8677777778 & -1.36667 & 1.366666667 & 0 & 3 \\
\hline 1.3666666667 & 1.8677777778 & -1.36667 & 1.3666666667 & 0 & 4 \\
\hline 1.3666666667 & 1.8677777778 & -1.36667 & 1.3666666667 I & 0 & 5 \\
\hline 1.3666666667 & 1.8677777778 & -1.36667 & 1.3666666667 & 0 & 6 \\
\hline 1.3666666667 & 1.8677777778 & -1.36667 & 1.3666666667 & 0 & 7 \\
\hline 0.098373984 & 0.1344444444 & -0.36667 & 1.3666666667 & 1 & 8 \\
\hline 42.63495935 & 58.267777778 & 7.633333 & 1.3666666667 & 9 & 9 \\
\hline 54.53739837 & 74.534444444 & 8.633333 & 1.3666666667 & 10 & 10 \\
\hline 1.95203252 & 2.6677777778 & 1.633333 & 1.3666666667 & 3 & 11 \\
\hline 1.3666666667 & 1.8677777778 & -1.36667 & 1.3666666667 & 0 & 12 \\
\hline 1.3666666667 & 1.8677777778 & -1.36667 & 1.3666666667 & 0 & 13 \\
\hline 0.293495935 & 0.401111111 & 0.633333 & 1.3666666667 & 2 & 14 \\
\hline 15.70813008 & 21.467777778 & 4.633333 & 1.3666666667 & 6 & 15 \\
\hline 9.659349593 & 13.20111111 & 3.633333 & 1.3666666667 & 5 & 16 \\
\hline 1.3666666667 & 1.8677777778 & -1.36667 & 1.3666666667 & 0 & 17 \\
\hline 1.3666666667 & 1.8677777778 & -1.36667 & 1.3666666667 & 0 & 18 \\
\hline 1.3666666667 & 1.8677777778 & -1.36667 & 1.3666666667 & 0 & 19 \\
\hline 1.3666666667 & 1.8677777778 & -1.36667 & 1.3666666667 & 0 & 20 \\
\hline 1.3666666667 & 1.8677777778 & -1.36667 & 1.3666666667 & 0 & 21 \\
\hline 1.3666666667 & 1.8677777778 & -1.36667 & 1.3666666667 & 0 & 22 \\
\hline 1.3666666667 & 1.8677777778 & -1.36667 & 1.3666666667 & 0 & 23 \\
\hline 1.3666666667 & 1.8677777778 & $\begin{array}{l}-1.36667 \\
\end{array}$ & 1.3666666667 & 0 & 24 \\
\hline 1.3666666667 & 1.8677777778 & -1.36667 & 1.3666666667 & 0 & 25 \\
\hline 1.3666666667 & 1.8677777778 & -1.36667 & 1.3666666667 & 0 & 26 \\
\hline 1.3666666667 & 1.8677777778 & -1.36667 & 1.3666666667 & 0 & 27 \\
\hline 1.3666666667 & 1.8677777778 & -1.36667 & 1.3666666667 & 0 & 28 \\
\hline 1.3666666667 & 1.8677777778 & -1.36667 & 1.3666666667 & 0 & 29 \\
\hline 163.2430894 & & & 39.63333333 & 41 & المجموع \\
\hline
\end{tabular}




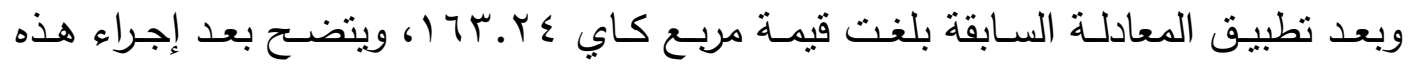

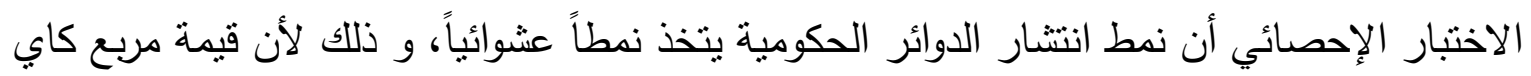
المحسوبة أكبر بكثبر من القيمة النظرية، كما في الجدول رقم (؟). جدول ( 7 ). نتائج حسابات مربع كاي لتوزيع الدوائر الحكومية على مناطق مدينة المفرق ثانياً: التحليل الكارتوغرافي

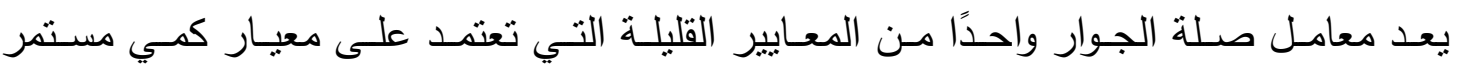
(Continuous)

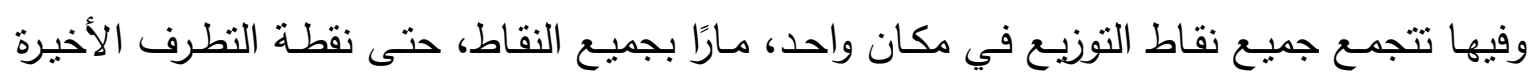

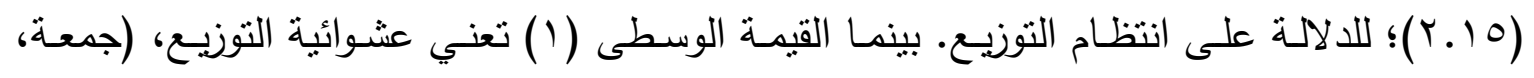

وقد تبين من خلال تطبيق تحليل معامل صلة الجوار على مواقع الدوائر الحكومية في مدينة المفرق

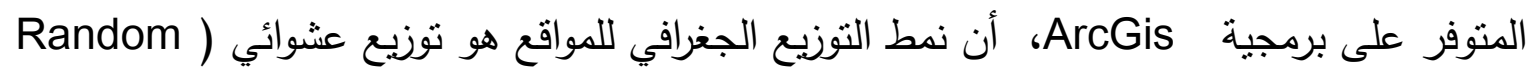

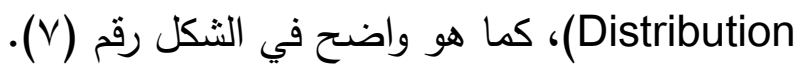

الثكل V. نمط التوزيع الجغرافي للاوائر الحكومية في مدينة المفرق.

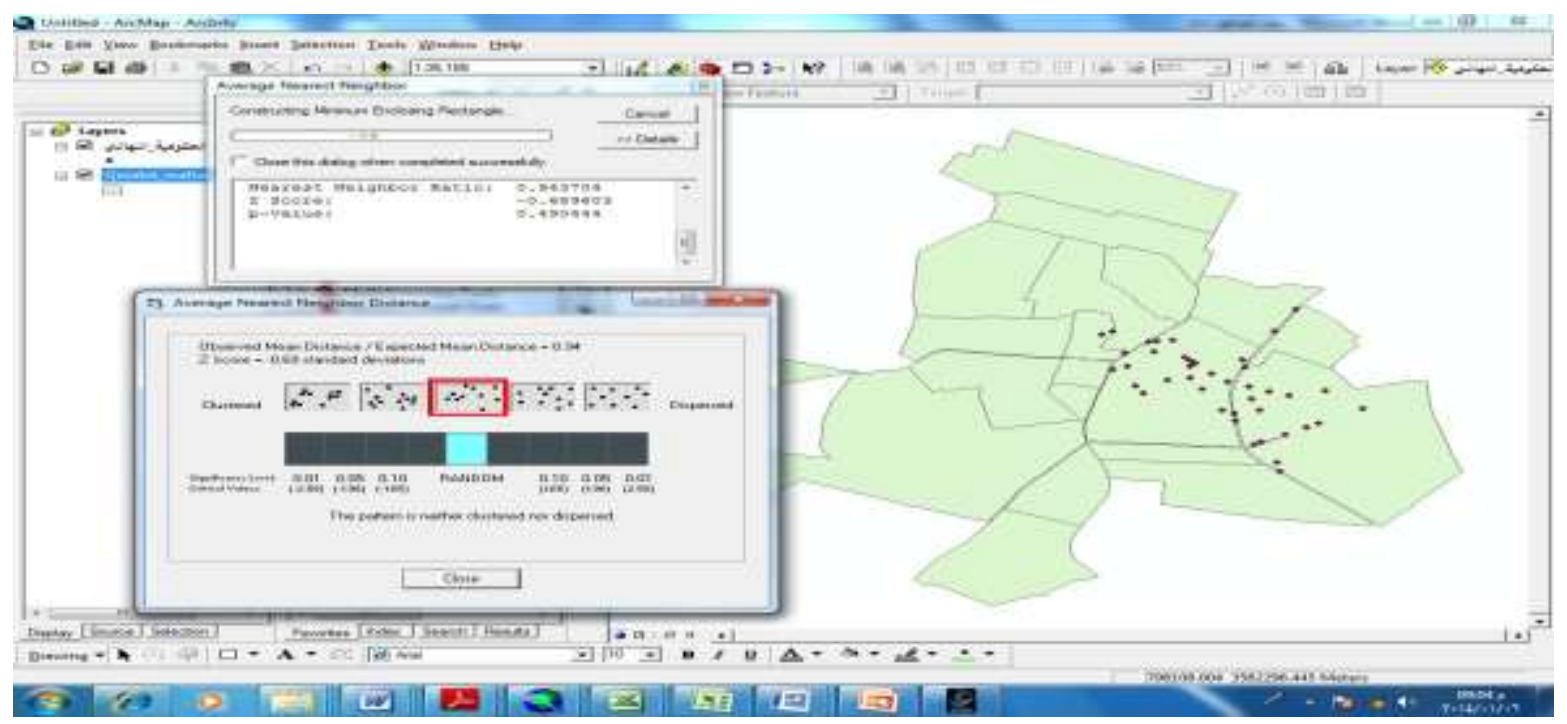




\section{r المسافة المعيارية Standard Distance}

تعدُّ هذه الوظيفية إحدى وظائف النزعة المركزية الهادفة للكثف عن الأنماط النقطية، بغرض إيجاد المركز المتوسط الذي يمتل مركز النقل للتوزيع المكاني للنقاط. ويقيس اختبار المسافة المعيارية شكل انتشـار المواقع حول مركزها المتوسط، من خـلال وصف مختزل لنكل انتشـار النقاط حول مركزها المتوسط. ومن خلال استخدام ملحق التحليل المكاني في برمجية نظم المعلومات المكانية؛ تم استخراج المركز المتوسط، وتحديد المسافة المعيارية، لمواقع الدوائر الحكومية في مدينة المفرق، كما بهاب

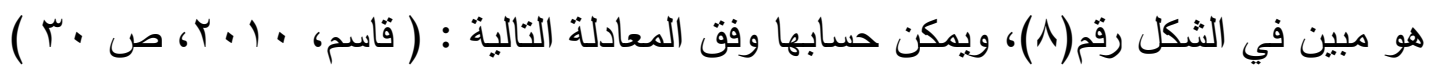

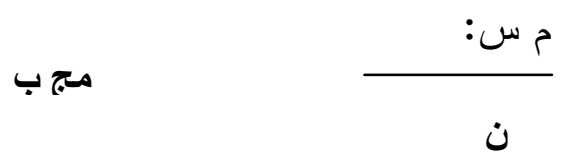

حيث م س : المسافة المعيارية. بr : مربع انحرافات إحداثيات الدوائر الحكومية في الددينة عن المركز المتوسط.

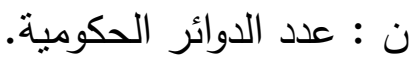
الثكل ^ـ المسافة المعيارية للدوائر الحكومية في مدينة المفرق.

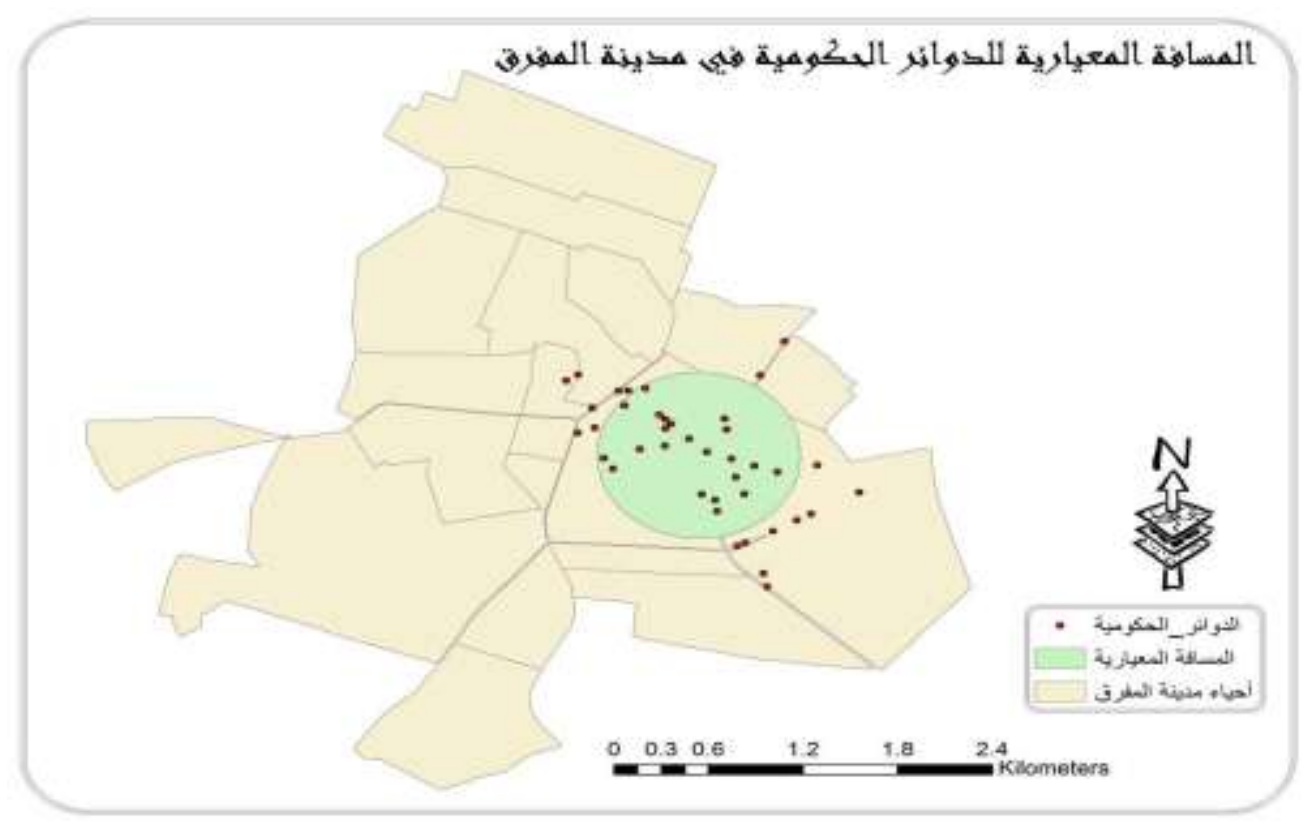


وقد تبين بعد تطبيق هذا الاختبار باستخدام برنامج ArcGis، أن المسافة المعيارية

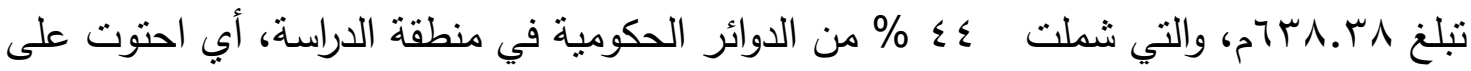

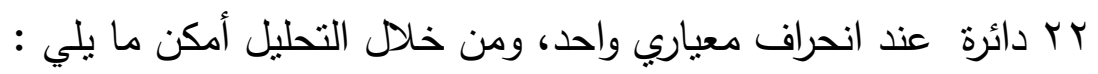
اتساع الدائرة الممثلة للمسافة المعيارية، مما يدل على أن نمط انتشار الدوائر الحكومية في منطقة الدراسة ييتعد عن التوزيع المتجمع.

انحراف المركز المتوسط نحو الثرق ليكون من ضمن حي النهضة، مما يعبر عن ازدياد عدد الدوائر الحكومية التي تتواجد ضمن هذا الحي.

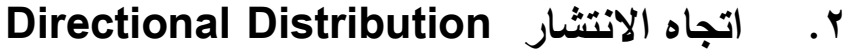

يعبر اتجـاه الانتشـار عن شكل توزع الدوائر الحكوميـة في منطقة الدراسـة من خـلال رسم شكل بيضـاوي يمثل شكل توزع مفردات الدراسـة. وقد تم استخدام تقنيـة الاتحراف المعيـاري البيضـاوي في الملحق Standard Deviational Ellipse) هذا الاختبار بأن اتجاه الانتشار شمال غربي و جنوبي شرقي، كما يبين الثكل رقم ( 1 ). الثكل ^. اتجاه الانتتار للدوائر الحكومية في مدينة المفرق.

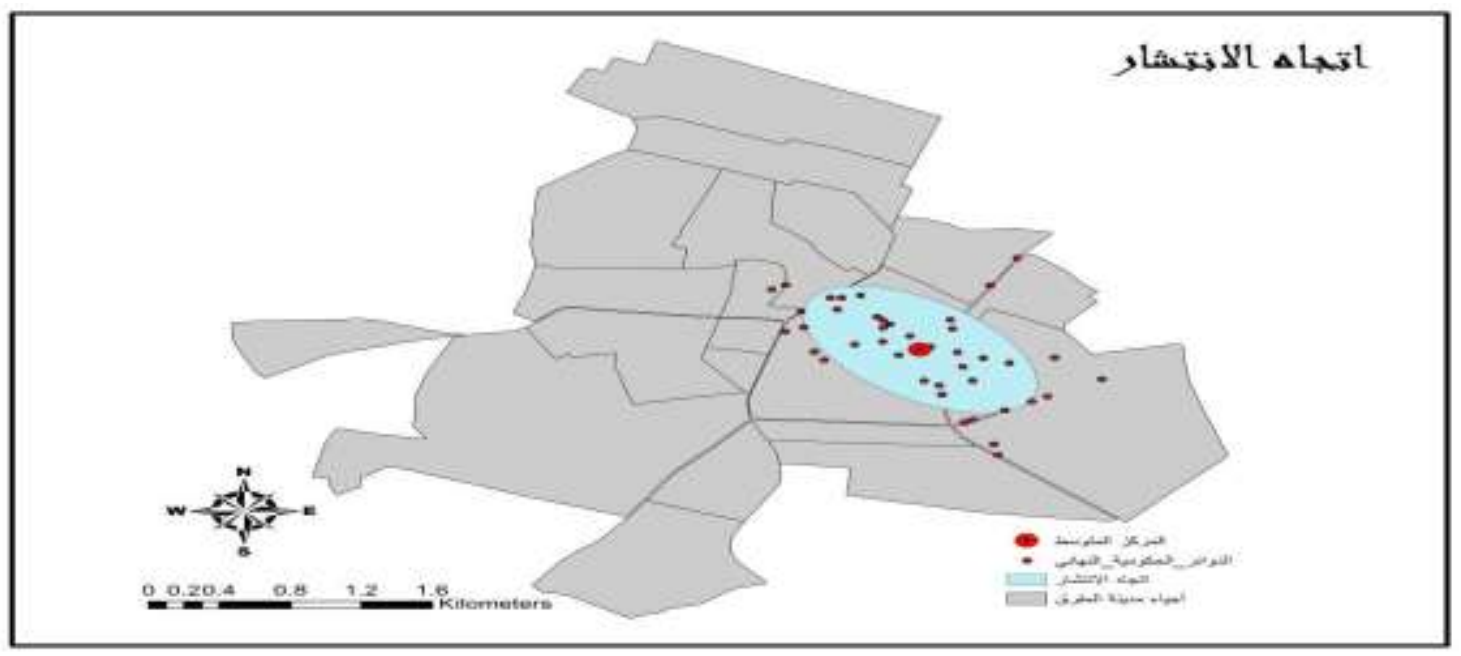

وتبين من خلال الشكل السابق أن 9 \% من مجمل الدوائر الحكومية تقع ضمن انحراف معياري واحد، والمفترض أن تكون نسبة الدوائر الحكومية ضمن انحراف معياري واحد هـ \% ـ كما 
يلحظ تركز الدوائر الحكومية ضمن انحراف معياري واحد في حي النهضة، والثهيد وصفي التل، الأمر الذي حدد شكل اتجاه انتشار الدوائر الحكومية.

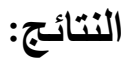

ا. أظهرت نتائج الدراسـة أن نمط توزيع الدوائر الحكوميـة اتخذ نمطاً عشوائياً وفق معامل صلة الجوار، و هذا ينفي فرضية توزع الدوائر بشكل منتظم.

r إ إن توزيع الدوائر الحكومية يتفق أحيانا مع توزيع السكان مثل حي النهضة الذي يسكنه حوالي

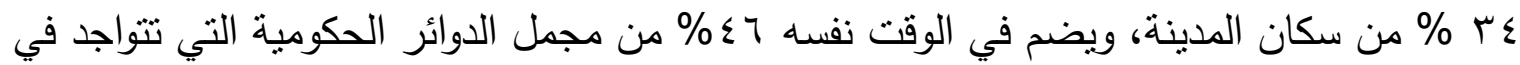
مدينة المفرق، لكن تجد المفارقة عندما تتواجد ^^\% من مجمل الدوائر الحكومية في حي الثهيد وصفي النل والذي يقطنه حوالي ( \% مـن إجمالي سكان مدينة المفرق، ويعود السبب في هذه منه العشوائية في هذا التوزيع إلى استحداث دوائر حكومية جديدة، وعدم توفر أراضي ملك للدولة مما اضطر الجهات الحكومية إلى استئجار أبنية بديلة كحل مؤقت، ومثنال ذلك دائرة الأحوال المدنية، وديوان المحاسبة، ومديرية العمل، ومديرية الأثغال العامة.

r. أظهرت نتائج التحليل الإحصائي أن العلاقة بين توزع السكان والدوائر الحكومية في مدينة المفرق

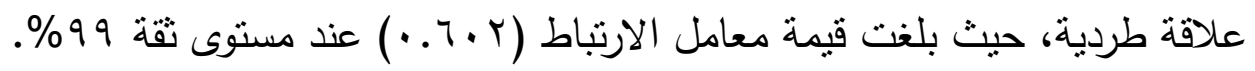
ع. أثبت تحليل المسافة المعيارية الذي يقيس مدى تكتل الدوائر المدروسة؛ أن أكثر من ؟ ؟\% من الدوائر الحكومية يقع ضمن انحراف معياري واحد من المركز المتوسط لهذه الدوائر. ه. تبين أن الاتجاه العام لانتتـار الدوائر الحكوميـة وامتدادها في مدينة المفرق كان شمالي غربي وجنوبي شرقي حيث ترتفع الكثافات السكانية في تلك الاتجاهات.

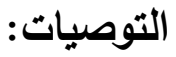

ا. نقل الدوائر الحكومية التي تتواجد في الأحياء ذات الكثافات السكانية القليلة إلى أحياء تتركز

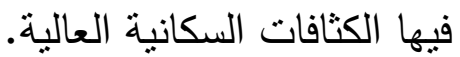

r. أنثاء مكاتب ارتباط فرعية في حالة عدم إمكانية نقل بعض الدوائر الحكومية. 
r. إنشاء منطقة دوائر حكومية كخطوة تخطيطية مستقبلية، تضم مختلف الدوائر الحكومبة التي تتواجد في مدينة المفرق، مع الأخذ بعين الاعتبار إمكانية استحداث دوائر حكومية جديدة في المستقبل.

\section{المصادر والمراجع:}

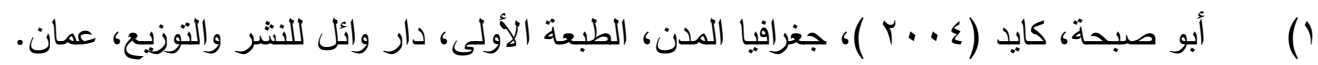

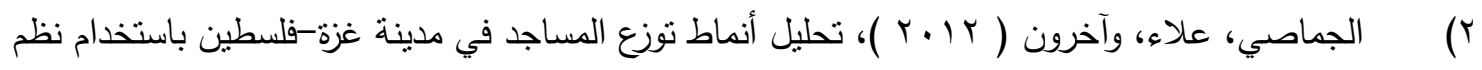

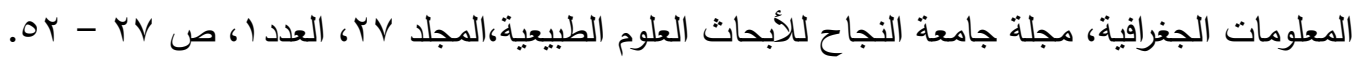

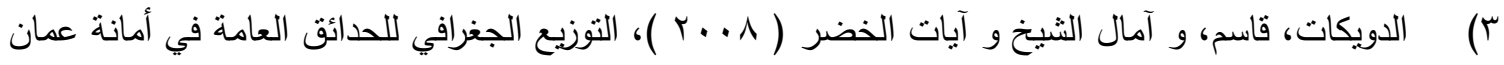

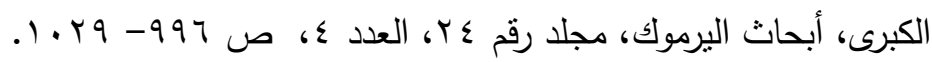

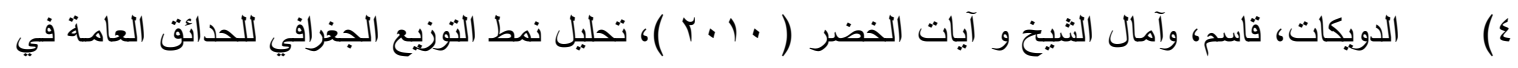

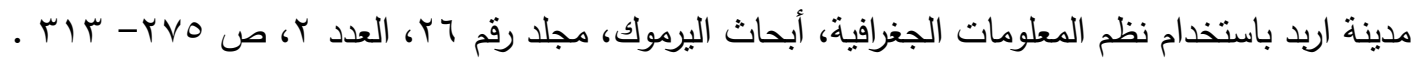

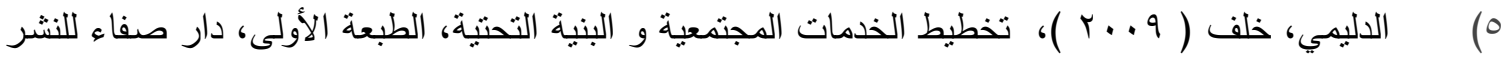
والتوزيع،عمان.

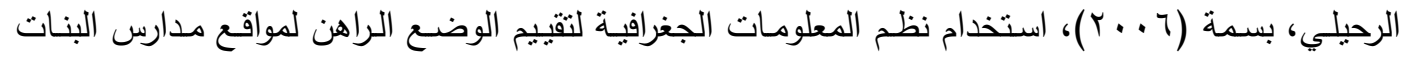
الحكومية بمدينة مكة المكرمة، جامعة أم القرى، مكة المكرمة.

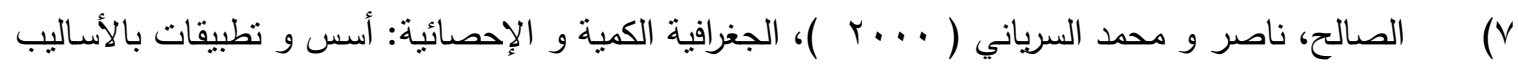
الحديثة، الطبعة الأولى، مكتبة العبيكان، الرياض، المملكة العربية السعودية.

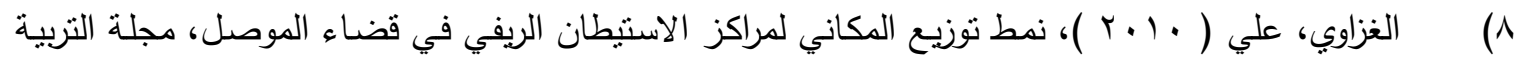

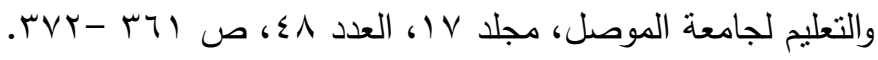

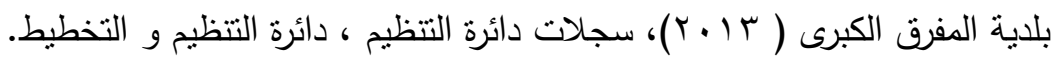
دائرة الإحصاءات العامة، الكتاب الإحصائي السنوي ( ب ـ ب )، عمان، دائرة الإحصاءات العامة. 


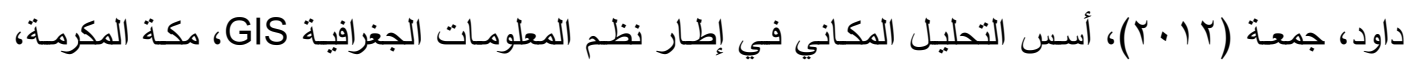

المملكة العربية السعودية.

r (1) شحادة، نعمان( (1999 )، مناخ الأردن،الطبعة الأولى،دار البشير للنشر و التوزيع، عمان.

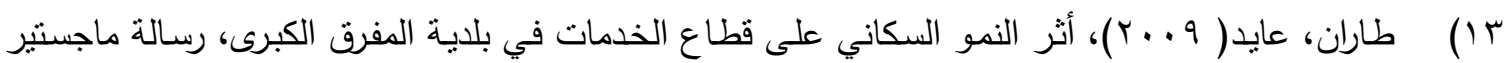
غير منشورة، الجامعة الأردنية، عمان.

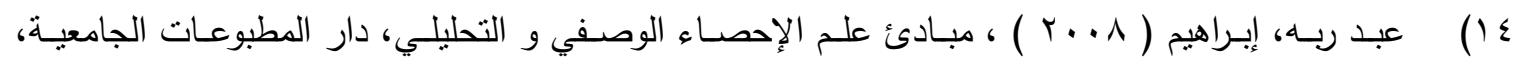
الإسكندرية، جمهورية مصر العربية.

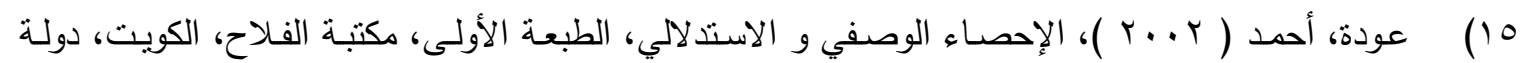
الكويت.

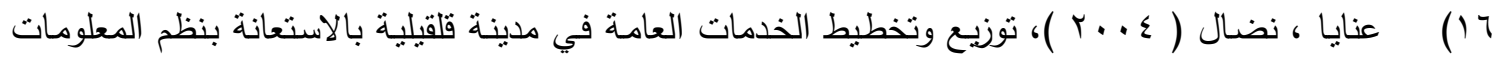
الجغرافية (GIS)، رسالة ماجستير غير منشورة، جامعة النجاح ، نابلس.

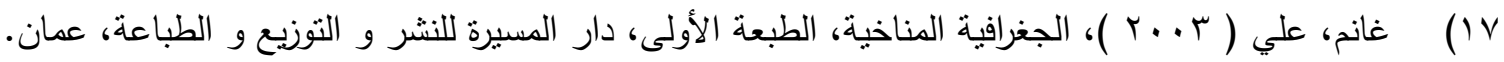

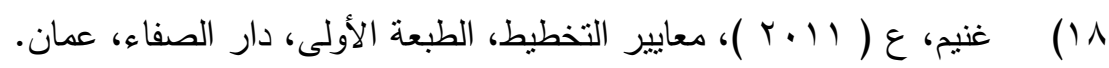

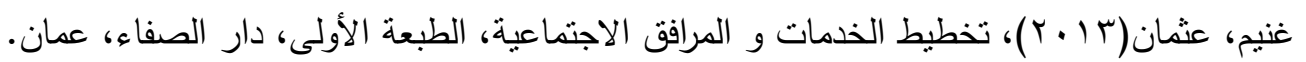

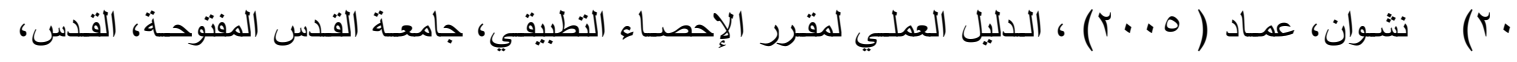
فلسطين.

\section{المراجع الأجنبية:}

1. Illian J, Penttinen A, Stoyan H, Stoyan D,2008, Statistical analysis and modeling of spatial point patterns, Wiley, London.

2 - Harvey, D.W.1973, Models of Evolution of spatial patterns in Human Geography in (spacing) Integrated Models in Geography.Lit by Chorly and Hagget, London.

3- Mitchell, A.2005, The ESRI Guide to GIS Analysis, Volume 2: Spatial easurements and Statistics. Redlands, CA: ESRI Press.

4-Jones B. Ch.1998, Geographical Information Systems and Computer Cartography. Longman, Singapore. 


\title{
Spatial Analysis of the Distribution of Governmental Departments in the City of Mafraq by Using GIS
}

\author{
A.M. Ayed Mohammad Ayed Taran \\ M.M. Atef Ayed Mohammad Algmeed \\ Alal-bayt University \Institute of Earth and Environmental Sciences \\ Taran0002002@yahoo.com
}

\begin{abstract}
:
This study seeks applying methodology of the spatial analysis of the governmental departments at the city of Mafraq by using geographic information systems technology (GIS), through spatial analysis tools that are available within the software environment of geographic information systems, which is characterized by its ability to spatial analysis data associated with a descriptive analytical database; in order to identify the characteristics of the place, through the study of spatial relationships for the geographical phenomenon, knowing the geographic distribution pattern for the geographical features, and their spreading on the surface of the earth.
\end{abstract}

This study relied on a descriptive analytical approach at digital data processing, through the use of some statistical methods, and graphic and cartographic representation, in order to highlight the spatial characteristics of the governmental departments at the city of Mafraq, as well as statistical analysis software (SPSS). The study concluded that there is a clear disparity in the geographical distribution for the government departments; as most of the government departments were located in the eastern side of the city of Mafraq. The study also showed that the distribution of these departments is random. Key words: Spatial analysis; government departments; geographic information systems; Nearest Neighbor, the standard distance, direction Distribution 